\title{
Preoperative In-Hospital Rehabilitation Improves Physical Function in Patients with Pancreatic Cancer Scheduled for Surgery
}

\author{
Yukio Mikami, ${ }_{1}^{1}$ Ken Kouda, ${ }^{1}$ Shinji Kawasaki, ${ }^{1}$ Ken-ichi Okada, ${ }^{2}$ Manabu Kawai, ${ }^{2}$ \\ Yuji Kitahata, ${ }^{2}$ Motoki Miyazawa, ${ }^{2}$ Seiko Hirono, ${ }^{2}$ Michiaki Unno, ${ }^{3}$ \\ Fumihiro Tajima ${ }^{1}$ and Hiroki Yamaue ${ }^{2}$
}

${ }^{1}$ Department of Rehabilitation Medicine, Wakayama Medical University, Wakayama, Wakayama, Japan

${ }^{2}$ Second Department of Surgery, Wakayama Medical University, Wakayama, Wakayama, Japan

${ }^{3}$ Department of Surgery, Tohoku University Graduate School of Medicine, Sendai, Miyagi, Japan

Low preoperative physical function in cancer patients is associated with postoperative complications; however, there have been no reports on the benefits of in-hospital preoperative rehabilitation on preoperative physical function in patients with pancreatic cancer. Therefore, the aim of this study was to quantitatively determine the effects of preoperative in-hospital rehabilitation provided under the supervision of a physiotherapist, on preoperative physical function in patients with pancreatic cancer. The study subjects were 26 patients (15 males, 11 females; age 71.2 \pm 8.5 years, range: $51-87$ years), including four patients with preoperative chemotherapy, scheduled for surgery for pancreatic cancer. Muscle strengthening exercises and aerobic exercises were conducted $11.9 \pm 5.1$ days prior to surgery. Cardiopulmonary exercise testing, 6-minute walk distance, and the Functional Independence Measure score were measured before and after the rehabilitation program. We also investigated the relation between the rehabilitation program and incidence of postoperative complications. All 26 study patients completed the preoperative rehabilitation program and no adverse events were noted. Peak oxygen uptake during cardiopulmonary exercise testing and 6-minute walk distance increased significantly after the rehabilitation program. The Functional Independence Measure score remained constant throughout the intervention. No wound infection, delirium, deep vein thrombosis, or respiratory complications were encountered postoperatively. In-hospital preoperative rehabilitation under the supervision of a physiotherapist significantly improved physical function and maintained physical activity in patients with pancreatic cancer. Such improvements may contribute toward preventing serious postoperative complications, resulting in better outcomes.

Keywords: pancreatic cancer; physical function; postoperative complications; preoperative rehabilitation; supervised rehabilitation

Tohoku J. Exp. Med., 2020 August, 251(4), 279-285.

\section{Introduction}

Pancreatic cancer is associated with poor prognosis but improvement in the survival rate has been reported recently thanks to advances in chemotherapy and surgical techniques (Burris et al. 1997). In addition, recent advances in preoperative chemotherapy for pancreatic cancer have improved the surgical resection rate (Hackert 2018; Motoi and Unno 2020). However, pancreatic cancer is often asso- ciated with poor physical function and activity (Yeo et al. 2012; Clauss et al. 2017), and preoperative chemotherapy can result in a further reduce reduction in the preoperative physical function and activity of the patients (West et al. 2014). In general, preoperative physical function in cancer patients correlate with postoperative complications, duration of hospitalization, and prognosis (Karlsson et al. 2018; Patel et al. 2019). Particularly in patients with pancreatic cancer, who receive pre and/or postoperative chemotherapy

Received April 21, 2020; revised and accepted July 8, 2020. Published online August 4, 2020; doi: 10.1620/tjem.251.279.

Correspondence: Yukio Mikami, M.D., Ph.D., Department of Rehabilitation Medicine, Wakayama Medical University, 811-1 Kimiidera,

Wakayama, Wakayama 641-8509, Japan.

e-mail: ymikami@wakayama-med.ac.jp

(C)2020 Tohoku University Medical Press. This is an open-access article distributed under the terms of the Creative Commons Attribution-NonCommercial-NoDerivatives 4.0 International License (CC-BY-NC-ND 4.0). Anyone may download, reuse, copy, reprint, or distribute the article without modifications or adaptations for non-profit purposes if they cite the original authors and source properly.

https://creativecommons.org/licenses/by-nc-nd/4.0/ 
and highly invasive surgery, the risk of poor postoperative outcomes is a major concern (Callejas et al. 2019). Therefore, it would be beneficial to improve preoperative physical function especially in patients with pancreatic cancer. So far, only a few studies have discussed the feasibility and benefits of home-based preoperative rehabilitation in patients with pancreatic cancer (Ngo-Huang et al. 2017; Parker et al. 2019). Although "perioperative" rehabilitation was reported to significantly reduce postoperative respiratory complications (Piraux et al. 2018; Kitahata et al. 2018), there have been no reports on the impact of in-hospital intensive preoperative rehabilitation, nor have there been any quantitative measurement of the effects of such rehabilitation in patients with pancreatic cancer.

Therefore, the purpose of this study was to especially focus on preoperative physical function and to quantitatively and confirmatively examine the therapeutic effects of an in-hospital preoperative rehabilitation program conducted under the supervision of a physiotherapist in patients with pancreatic cancer, including patients who received preoperative chemotherapy.

Specifically, we tested the hypothesis that preoperative rehabilitation significantly enhances preoperative physical function, which in turn improves activities of daily living (ADL), quality of like (QOL), and likely improve postoperative outcome. If this hypothesis is supported by our results, then this study could be a novel link between the fields of pancreatic surgery and rehabilitation medicine. This has the potential to provide basis for further studies, and complement a new strategy to treat patients with pancreatic cancer.

\section{Methods}

Study design

Single arm before-after study

\section{Subjects}

The subjects were patients with pancreatic cancer who visited the Department of Rehabilitation Medicine, Wakayama Medical University, between January 2016 and December 2018. The inclusion criteria were (1) patients scheduled for surgery, and (2) patients who agreed to provide informed consent. The exclusion criteria were (1) patients with difficulty exercising due to associated musculoskeletal disorders, (2) patients with advanced dementia and mental disorders, and (3) patients with unstable respiratory and/or circulatory disorders. No control patients were enrolled for ethical reasons.

\section{Training program}

Each subject was admitted to the Department of Rehabilitation Medicine before surgery, and upon admission, under the supervision of a physical therapist performed muscle strengthening exercises of squatting (300 times/day), heel raising (100 times/day), and step up and down (100 times/day), as well as aerobic exercise including cycle ergometry (30 $\mathrm{min} /$ day), hand grip ergometry (20 $\mathrm{min} /$ day $)$, and treadmill walking (20 $\mathrm{min} /$ day) every day until one day before surgery (Fig. 1). The intensity of cycle ergometry training, hand ergometry, and treadmill walking training was adjusted to 11-13 on the Borg scale (Morishita et al. 2018).
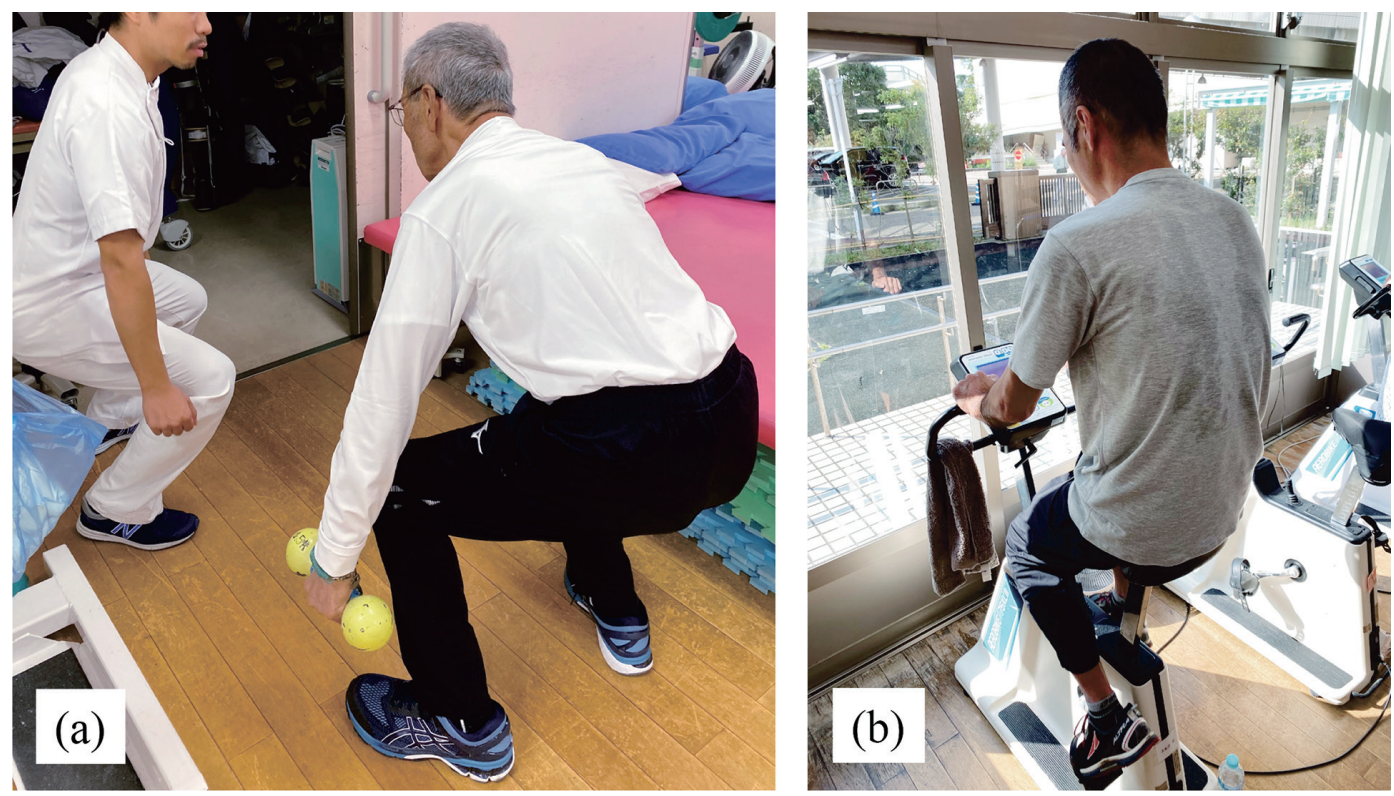

Fig. 1. Preoperative rehabilitation program applied in this study.

(a) Muscle strengthening exercise (squat training). (b) Aerobic exercise (cycle ergometer training). The subject was admitted to the Department of Rehabilitation Medicine, and under the guidance of a physical therapist, squat training (Fig. 1a), heel raise training, step up and down training (muscle strengthening exercise) and cycle ergometer training (Fig. 1b), hand ergometer training, treadmill walking training (aerobic exercise) were conducted before surgery. 


\section{Outcome measures}

Cardiopulmonary exercise testing (CPET), the 6-minute walk test (6MWT), and scoring of the Functional Independence Measure (FIM) were conducted before and after preoperative rehabilitation to evaluate the effects of preoperative rehabilitation program. In addition, any postoperative complications that appeared during hospitalization as well as the total length of hospital stay and survival days were recorded.

\section{Cardiopulmonary Exercise Testing}

CPET is a comprehensive and established stress test designed to evaluate oxygen utilization and oxygen transport capacity in active muscles, based on breath-by-breath gas analysis (Weisman et al. 2003). Using an aero monitor AE-310S (Minato Medical Science Co., Osaka, Japan) and cycle ergometer, the subject was rested for 3 minutes and warmed up at 20 watts for 3 minutes. After that, the subject exercised during the application of a ramp load (20 watts/ min), until exhaustion. During the exercise, we measured blood pressure and recorded the electrocardiogram, in addition to the breath-by-breath gas analysis. The anaerobic threshold (AT) point was determined by the V-slope method (Beaver et al. 1986), and also confirmed by the trend method (Orr et al. 2013). Furthermore, AT oxygen uptake $\left(\dot{\mathrm{VO}}_{2}\right)$, AT heart rate (HR), and AT WR (Work rate) were measured in the same test. In addition, $\dot{\mathrm{VO}} 2, \mathrm{HR}$, and $\mathrm{WR}$ at exhaustion were determined as Peak $\dot{\mathrm{VO}}_{2}$, Peak HR, and Peak WR, respectively. In this regard, Davies and Danjoux (2010) reported that $\mathrm{AT} \dot{\mathrm{VO}}_{2}$ and Peak $\dot{\mathrm{VO}}_{2}$ are indicators of endurance in surgery.

\section{The 6-minute walk test}

The 6MWT is a self-paced test that evaluates endurance and gait function as endorsed by the American Thoracic Society (ATS). According to the ATS guideline (Brooks et al. 2003), we used a 30-m straight course with a cone at the turning point in the present study. The procedure of the 6MWT was as follows: (1) the subject avoided strenuous exercises 2 hours before the test and did not do any warm up maneuvers; (2) the subject rested on a chair for at least 10 minutes before the test; (3) heart rate and blood pressure were recorded; (4) the subject was checked to ensure that $\mathrm{s} /$ he can walk as much as possible and advised not to run during the test, immediately before the start of the test; (5) the examiner walked diagonally behind the subject; (6) the subject was informed only of the time that passed during the test; and (7) after walking as fast as possible for 6 minutes, the examiner recorded the total 6-minute walking distance (6MWD).

\section{Functional Independence Measure}

The FIM is an index of the degree of independence in ADL. It scores 18 activities using a scale of 1 to 7 , and the sum of scores of total score is determined (range: 18-126) (Senda et al. 2019). The higher the FIM score, the more independent is the patient is in daily life.

\section{Statistical analysis}

Continuous variables were expressed as mean \pm standard deviation (SD). We showed the age-related values according to the redefinition of elderly (aged 75 years and older) by the Joint Committee of Japan Gerontological Society and the Japan Geriatrics Society (Ouchi et al. 2017). A paired t-test was used to compare differences in the values of CPET and 6MWD before and after preoperative rehabilitation, with significance set at $p<0.05$. All data were analyzed using JMP $\AA$ pro version 14.1 (SAS Institute Inc.). This study was approved by the Research Ethics Review Committee of Wakayama Medical University (\#1174) and each subject provided signed consent before enrolment into the study.

\section{Results}

The study subjects were 26 (15 males, 11 females; age $71.2 \pm 8.5$ years, range: $51-87$ years) who met the above inclusion/exclusion criteria. Demographic characteristics of the patients are shown in Table 1. Pancreatic cancer was located in the head of the pancreas in 14 cases and in the tail of the body of the pancreas in 12. The stage of pancreatic cancer (UICC classification version 7 th) was Stage 0 in 1, Stage IA in 1, Stage IB in 1, Stage IIA in 10 and Stage IIB in 13 cases. Four patients $(15 \%)$ were on preoperative chemotherapy while they underwent the rehabilitation program. The rehabilitation program was conducted $11.9 \pm 5.1$ days before surgery, and all subjects completed the program. No adverse events were observed during the preoperative rehabilitation.

Fig. 2 shows the results of CPET in a representative patient (76-year-old man). On the $\mathrm{V}$-slope view, the point where carbon dioxide output $\left(\dot{\mathrm{V}} \mathrm{CO}_{2}\right)$ increased relative to $\dot{\mathrm{VO}}{ }_{2}$ was determined as the AT point. Analysis of the time trend view showed an increase in the ventilatory equivalent for oxygen $\left(\dot{\mathrm{VE}} / \dot{\mathrm{V}} \mathrm{O}_{2}\right)$ without any increase in the ventilatory equivalent for carbon dioxide $\left(\dot{\mathrm{VE}} / \mathrm{V} \mathrm{CO}_{2}\right)$ at that point. The results of CPET in this patient were as follows: $\mathrm{AT} \dot{\mathrm{VO}} 2$ $15.0 \mathrm{~mL} / \mathrm{kg} / \mathrm{min}$; AT HR 121 beats/min; AT WR 75 watts; Peak $\dot{\mathrm{VO}}_{2} 25.4 \mathrm{~mL} / \mathrm{kg} / \mathrm{min}$; Peak HR 155 beats/min; and Peak WR137 watts.

The age- and sex-related CPET values of the entire study subjects are summarized in Table 2. All Peak values were significantly higher after rehabilitation compared with before rehabilitation (Paired t-test, $\mathrm{p}<0.05$ ) regardless of age or sex, although a significant difference was found only in the values for males and under 75 years old at the AT point.

The 6MWD before rehabilitation was $498.7 \pm 63.0$ in males, $462.6 \pm 66.0$ in females, $515.8 \pm 58.6$ in patients under 75 years old, $439.4 \pm 49.7$ in patients over 75 years old and the value after rehabilitation was $529.5 \pm 72.2$ in male, $497.5 \pm 68.0$ in female, $551.9 \pm 60.5$ in patients under 75 years old, and $467.0 \pm 56.3$ in patients over 75 years old, 
Table 1. Demographic characteristics of patients $(n=26)$.

\begin{tabular}{lcc}
\hline Age $($ mean \pm SD) & & $71.2 \pm 8.5$ \\
\hline Gender N (\%) & Male & $15(58)$ \\
& Female & $11(42)$ \\
\hline Stage N (\%) (UICC classification version 7th) \\
0 & $1(4)$ \\
IA & $1(4)$ \\
IB & $1(4)$ \\
IIA & $10(38)$ \\
IIB & $13(50)$ \\
\hline
\end{tabular}

Pre-operative chemotherapy n $(\%)$

$\begin{array}{rr}(+) & 22(85) \\ (-) & 4(15)\end{array}$

Operation $n(\%)$

$\begin{array}{rc}\text { PrPD } & 14(54) \\ \text { DP } & 10(38) \\ \text { Laparoscopic DP } & 2(8)\end{array}$

UICC, Union for International Cancer Control; PrPD, pylorus-resecting pancreatoduodenectomy; DP, pancreatic body and tail resection.

respectively. All 6MWD values increased significantly after rehabilitation compared to before rehabilitation (Paired t-test, $\mathrm{p}<0.05)$. Furthermore, the FIM score was maintained, at $125.9 \pm 0.3$ before preoperative rehabilitation and $125.3 \pm 0.3$ after preoperative rehabilitation. Notably, the results of the four patients who received the preoperative chemotherapy were similarly effective compared with those without preoperative chemotherapy.

Surgery was performed after the preoperative rehabili- tation, including pylorus-resecting pancreatoduodenectomy $(\mathrm{n}=14)$, pancreatic body and tail resection $(\mathrm{n}=10)$, and laparoscopic pancreatic body and tail resection $(\mathrm{n}=2)$. Postoperatively, paralytic ileus was observed in one patient, though it improved with conservative management. No wound infection, delirium, deep vein thrombosis, or respiratory complications were encountered postoperatively. The mean length of hospital stay for all study subjects was $16.4 \pm 7.6$ days, and by June 2020, four patients had died from pancreatic cancer (postoperative survival days, 532.3 \pm 227.8 days), while the other 22 patients survived (871.3 \pm 263.9 days after surgery).

\section{Discussion}

This study is the first to primarily focus on preoperative physical function and to quantitatively evaluate the effects of a preoperative rehabilitation program provided under the supervision of a physical therapist, in patients scheduled to undergo surgery for pancreatic cancer. All patients, even those with preoperative chemotherapy, completed the intensive rehabilitation program without adverse effects, and all Peak values of CPET and 6MWD increased significantly after the completion of the program. The FIM score, an indicator of activity, remained stable throughout the study. Further follow-up showed no respiratory or serious complications after surgery in these patients.

Only a few studies have examined the effect of perioperative rehabilitation in patients with certain types of cancers, e.g., esophageal cancer, whereas several studies analyzed the effects of rehabilitation applied after surgery (Quist et al. 2018; Hanada et al. 2018). The enhanced recovery after surgery (ERAS) protocol has been attracting attention in recent years. ERAS promotes postoperative recovery by introducing various patient care programs in an

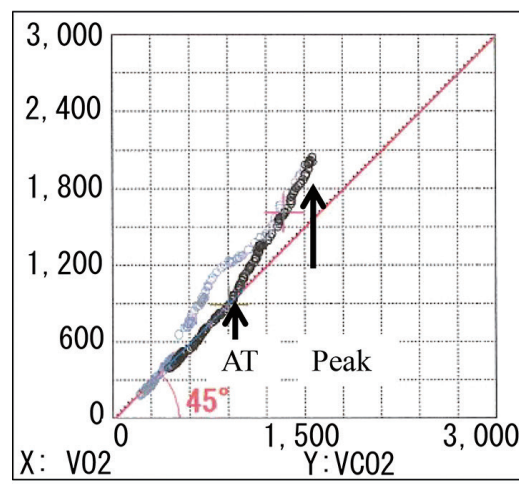

(a)

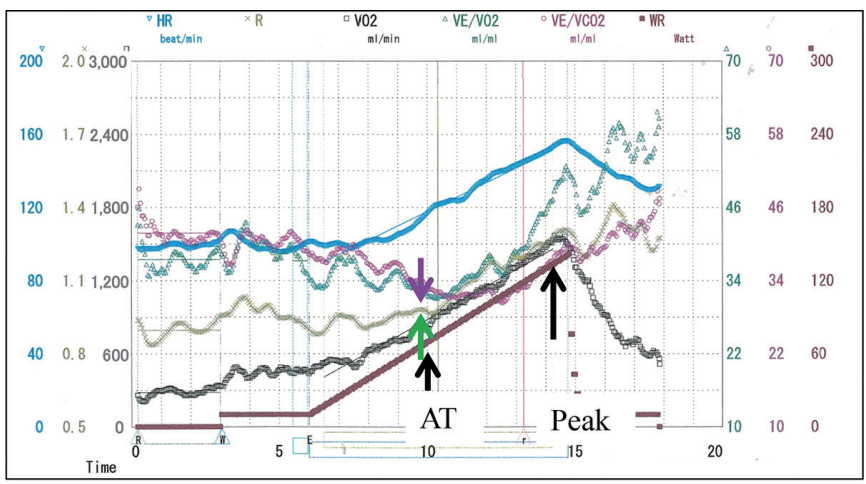

(b)

Fig. 2. Results of cardiopulmonary exercise testing (CPET) in a 76-year-old man.

(a) V-slope view, (b) Time trend view. Black short arrow indicates the anaerobic threshold (AT) point and black long arrow shows peak point in each view. The AT point was determined by the V-slope view and also confirmed by the trend view. On the V-slope view, the point where carbon dioxide output $\left(\dot{\mathrm{VCO}}_{2}\right)$ was increased relative to oxygen uptake $\left(\dot{\mathrm{V}}_{2}\right)$ was determined as the AT point. The time trend view shows an increase in the ventilatory equivalent for oxygen $\left(\dot{\mathrm{VE}} / \dot{\mathrm{VO}}_{2}\right.$, green arrow) without any increase in the ventilatory equivalent for carbon dioxide $\left(\dot{\mathrm{VE}} / \mathrm{VCO}_{2}\right.$, purple arrow) at that point. Data at the time of exhaustion were considered the peak points.

AT, anaerobic threshold point; Peak, peak point; HR, heart rate; R, respiratory exchange ratio; $\dot{\mathrm{V}} \mathrm{O}_{2}$, oxygen uptake; $\dot{\mathrm{V} E}$ / $\dot{\mathrm{V}} \mathrm{O}_{2}$, the ventilatory equivalent for oxygen; $\dot{\mathrm{V} E} / \dot{\mathrm{V}} \mathrm{CO}_{2}$, the ventilatory equivalent for carbon dioxide; WR, work rate. 
Table 2. Results of Cardiopulmonary exercise testing (CPET) $(n=26)$.

\begin{tabular}{|c|c|c|c|c|c|c|c|c|}
\hline \multirow{2}{*}{ Index } & \multicolumn{4}{|c|}{ Before } & \multicolumn{4}{|c|}{ After } \\
\hline & $\begin{array}{c}\text { Male } \\
(\mathrm{n}=15)\end{array}$ & $\begin{array}{l}\text { Female } \\
(\mathrm{n}=11)\end{array}$ & $\begin{array}{c}75< \\
(n=15)\end{array}$ & $\begin{array}{c}75 \geq \\
(n=11)\end{array}$ & $\begin{array}{c}\text { Male } \\
(\mathrm{n}=15)\end{array}$ & $\begin{array}{l}\text { Female } \\
(\mathrm{n}=11)\end{array}$ & $\begin{array}{c}75< \\
(\mathrm{n}=15)\end{array}$ & $\begin{array}{c}75 \geq \\
(n=11)\end{array}$ \\
\hline AT $\dot{\mathrm{VO}} 2(\mathrm{ml} / \mathrm{min} / \mathrm{kg})$ & $15.3(3.1)$ & $16.6(3.3)$ & $16.1(3.0)$ & $14.9(2.9)$ & $16.2 *(2.3)$ & $16.8(3.7)$ & $17.2 *(3.2)$ & $15.8(2.2)$ \\
\hline AT HR (beat/min) & $104.7(13.8)$ & $109.8(17.0)$ & $108.0(17.1)$ & $107.3(14.1)$ & $111.1^{*}(14.2)$ & $116.7(14.1)$ & $115.0 *(15.9)$ & 110.6 (11.9) \\
\hline AT WR (watt) & $67.4(16.8)$ & $56.4(13.0)$ & $63.9(16.8)$ & $61.8(16.6)$ & $73.9 *(16.1)$ & $57.5(16.0)$ & $72.3 *(18.9)$ & $62.1(12.9)$ \\
\hline Peak V்O2 $(\mathrm{ml} / \mathrm{min} / \mathrm{kg})$ & $20.4(4.9)$ & $18.0(5.0)$ & $22.2(4.9)$ & $16.4(4.2)$ & $22.4 *(5.0)$ & $20.0 *(5.5)$ & $23.9 *(5.0)$ & $17.8 *(3.7)$ \\
\hline Peak HR (beat/min) & $141.7(17.9)$ & $140.5(23.7)$ & $146.6(17.9)$ & $135.8(23.3)$ & $149.7 *(14.8)$ & $147.6 *(24.8)$ & $158.2 *(13.8)$ & $143.6 *(18.8)$ \\
\hline Peak WR (watt) & $116.4(29.2)$ & $98.9(14.1)$ & $118.8(4.9)$ & $95.6(19.0)$ & $127.7 *(25.6)$ & $113.3 *(19.9)$ & $130.5 *(21.9)$ & $109.5 *(22.2)$ \\
\hline
\end{tabular}

Data are mean (SD).

Standard value: AT VंO2, 15.3-16.1 ml/min/kg; Peak VंO2, 21.2-26.2 ml/min/kg; Peak HR, 133-169 beat/min.

AT, anaerobic threshold point; $\dot{\mathrm{V} O}$, oxygen uptake; HR, heart rate; WR, work rate; Peak, peak point.

*Paired t-test: $\mathrm{p}<0.05$ vs. before-rehabilitation.

integrated manner based on evidence (Aoyama et al. 2018; Low et al. 2019). ERAS is designed to achieve the following three goals: (1) reduction of surgical invasion; (2) prevention of surgical complications; and (3) promotion of early postoperative recovery, thereby shortening the length of hospital stay and achieving an early return to society. Among the 17 main elements of the ERAS protocol, early mobilization is among the postoperative factors, but preoperative rehabilitation guided by a physical therapist is not included in the preoperative factors. Since reports of preoperative rehabilitation for cancer patients are increasing (Bhatia and Kayser 2019; Barrett-Bernstein et al. 2019), Milalpeix et al. (2019) proposed the addition of preoperative rehabilitation to the ERAS protocol.

With regard to preoperative rehabilitation of patients with pancreatic cancer, only two questionnaire-based studies reported previously the results of self-training at home before surgery (Ngo-Huang et al. 2017; Parker et al. 2019). They demonstrated the feasibility and adherence of home self-training, and consequent improvement in physical activity of the patients who had low baseline physical activity. However, in their reports, home self-training did not improve physical function, which was probably due to the low exercise intensity used in the self-training program. The study of Wiskemann et al. (2019) compared the effects of muscle strength training under the supervision of a physical therapist with those of home self-training in patients with pancreatic cancer. The results showed that muscle strength training guided by the therapist significantly increased muscle strength compared to self-training. The results of the present study confirm the above findings and indicate that preoperative rehabilitation prescribed by a rehabilitation specialist and supervised by a therapist significantly improves preoperative physical function, measured quantitatively, in patients with pancreatic cancer.

Previous studies also examined the relation between preoperative physical function and postoperative outcome in cancer patients. One study reported a close correlation between the results of preoperative CPET and postoperative outcome in patients with pancreatic cancer (Junejo et al.
2014), while another concluded that preoperative 6MWD was a predictor of postoperative complications in patients with hepatobiliary pancreatic cancer (Hayashi et al. 2017). Furthermore, a systematic review by Kumar and Garcea (2018) showed poor postoperative recovery in hepatobiliary pancreatic cancer patients with $\mathrm{AT} \dot{\mathrm{V}} \mathrm{O}_{2}$ of $\leq 10.5 \mathrm{~mL} / \mathrm{kg} /$ min on preoperative CPET. Thus, in patients with pancreatic cancer, preoperative physical functions, particularly the values on CPET and the 6MWD, seem to correlate with postoperative outcome. In the present study, both the CPET scores and 6MWD improved following preoperative rehabilitation in patients with pancreatic cancer, and that such program was not associated with serious complications after surgery. While it is likely that the improved preoperative physical function resulting from the preoperative rehabilitation prevented the development of serious postoperative complications, further studies are needed to confirm this finding and determine the mechanisms of such improvement.

The present study has certain limitations. First, the study was a single-arm, before and after study, which did not include a control group. In this regard, the effect of perioperative rehabilitation has already been recognized, and it was ethically difficult to include a control group. Second, our study did not measure nutritional status but rather focused solely on physical function and activity. It is necessary to measure nutritional status throughout the period of preoperative rehabilitation, including nutritional intervention. Third, in this study, the physical therapist in charge and the duration of preoperative rehabilitation were not fixed. Although the preoperative rehabilitation program was provided as part of the standard clinical treatment, our results could be viewed as the effect of rehabilitation plus the clinical care. Lastly, our study primarily focused on preoperative physical function, which are the goals of rehabilitation treatment, since postoperative results are affected several factors such as the extent of the malignancy, surgical procedure, operation time, anesthesia, and postoperative chemotherapy,

Although the number of subjects who received preop- 
erative chemotherapy for pancreatic cancer was low, the present preliminary study demonstrated the feasibility of a preoperative in-hospital rehabilitation program and its quantitatively measured beneficial effects on preoperative physical function and activity in patients with preoperative chemotherapy, which may lead to better postoperative outcomes. However, further studies are necessary to further analyze the effects of preoperative rehabilitation in patients scheduled for preoperative chemotherapy and the relationships between such rehabilitation and postoperative complications and prognosis.

In conclusion, the present study quantitatively examined the effects of preoperative rehabilitation prescribed by a rehabilitation specialist and conducted under the supervision of a therapist on preoperative physical function in patients with pancreatic cancer. Our preoperative rehabilitation program was associated with improvement in preoperative physical function and maintained physical activity in patients with pancreatic cancer, even in patients with preoperative chemotherapy. Such improvements may potentially contribute to the low incidence of postoperative complications, resulting in better outcomes.

\section{Acknowledgments}

We would like to thank Editage (https://www.editage. com) for English language editing.

\section{Conflict of Interest}

The authors declare no conflict of interest.

\section{References}

Aoyama, T., Kazama, K., Murakawa, M., Atsumi, Y., Shiozawa, M., Ueno, M., Morimoto, M., Taniguchi, H., Masuda, M. \& Morinaga, S. (2018) Safety and feasibility of enhanced recovery after surgery in the patients underwent distal pancreatectomy for pancreatic cancer. J. Cancer Res. Ther., 14, S724-S729.

Barrett-Bernstein, M., Carli, F., Gamsa, A., Scheede-Bergdahl, C., Minnella, E., Ramanakumar, A.V. \& Tourian, L. (2019) Depression and functional status in colorectal cancer patients awaiting surgery: impact of a multimodal prehabilitation program. Health Psychol., 38, 900-909.

Beaver, W.L., Wasserman, K. \& Whipp, B.J. (1986) A new method for detecting anaerobic threshold by gas exchange. J. Appl. Physiol. (1985), 60, 2020-2027.

Bhatia, C. \& Kayser, B. (2019) Preoperative high-intensity interval training is effective and safe in deconditioned patients with lung cancer: a randomized clinical trial. J. Rehabil. Med., 51, 712-718.

Brooks, D., Solway, S. \& Gibbons, W.J. (2003) ATS statement on six-minute walk test. Am. J. Respir. Crit. Care Med., 167, 1287.

Burris, H.A. 3rd, Moore, M.J., Andersen, J., Green, M.R., Rothenberg, M.L., Modiano, M.R., Cripps, M.C., Portenoy, R.K., Storniolo, A.M., Tarassoff, P., Nelson, R., Dorr, F.A., Stephens, C.D. \& Von Hoff, D.D. (1997) Improvements in survival and clinical benefit with gemcitabine as first-line therapy for patients with advanced pancreas cancer: a randomized trial. J. Clin. Oncol., 15, 2403-2413.

Callejas, G.H., Concon, M.M., Rezende, A.Q.M., Chaim, E.A., Callejas-Neto, F. \& Cazzo, E. (2019) Pancreaticoduodenec- tomy with venous resection: an analysis of 30-day morbidity and mortality. Arq. Gastroenterol., 56, 246-251.

Clauss, D., Tjaden, C., Hackert, T., Schneider, L., Ulrich, C.M., Wiskemann, J. \& Steindorf, K. (2017) Cardiorespiratory fitness and muscle strength in pancreatic cancer patients. Support. Care Cancer, 25, 2797-2807.

Davies, S.H. \& Danjoux, G.R. (2010). Preoperative assessment of patients for vascular surgery. Anesth. Intensive Care, 11, $170-173$

Hackert, T. (2018) Surgery for pancreatic cancer after neoadjuvant treatment. Ann. Gastroenterol. Surg., 2, 413-418.

Hanada, M., Kanetaka, K., Hidaka, S., Taniguchi, K., Oikawa, M., Sato, S., Eguchi, S. \& Kozu, R. (2018) Effect of early mobilization on postoperative pulmonary complications in patients undergoing video-assisted thoracoscopic surgery on the esophagus. Esophagus, 15, 69-74.

Hayashi, K., Yokoyama, Y., Nakajima, H., Nagino, M., Inoue, T., Nagaya, M., Hattori, K., Kadono, I., Ito, S. \& Nishida, Y. (2017) Preoperative 6-minute walk distance accurately predicts postoperative complications after operations for hepato-pancreato-biliary cancer. Surgery, 161, 525-532.

Junejo, M.A., Mason, J.M., Sheen, A.J., Bryan, A., Moore, J., Foster, P., Atkinson, D., Parker, M.J. \& Siriwardena, A.K. (2014) Cardiopulmonary exercise testing for preoperative risk assessment before pancreaticoduodenectomy for cancer. Ann. Surg. Oncol., 21, 1929-1936.

Karlsson, E., Egenvall, M., Farahnak, P., Bergenmar, M., NygrenBonnier, M., Franzén, E. \& Rydwik, E. (2018) Better preoperative physical performance reduces the odds of complication severity and discharge to care facility after abdominal cancer resection in people over the age of 70: a prospective cohort study. Eur. J. Surg. Oncol., 44, 1760-1767.

Kitahata, Y., Hirono, S., Kawai, M., Okada, K.I., Miyazawa, M., Shimizu, A., Kobayashi, R., Ueno, M., Hayami, S., Shimokawa, T., Kouda, K., Tajima, F. \& Yamaue, H. (2018) Intensive perioperative rehabilitation improves surgical outcomes after pancreaticoduodenectomy. Langenbecks Arch. Surg., 403, 711-718.

Kumar, R. \& Garcea, G. (2018) Cardiopulmonary exercise testing in hepato-biliary \& pancreas cancer surgery: a systematic review: are we any further than walking up a flight of stairs? Int. J. Surg., 52, 201-207.

Low, D.E., Allum, W., De Manzoni, G., Ferri, L., Immanuel, A., Kuppusamy, M., Law, S., Lindblad, M., Maynard, N., Neal, J., Pramesh, C.S., Scott, M., Mark Smithers, B., Addor, V. \& Ljungqvist, O. (2019) Guidelines for perioperative care in esophagectomy: Enhanced Recovery After Surgery (ERAS ${ }^{\circledR}$ ) Society recommendations. World J. Surg., 43, 299-330.

Miralpeix, E., Mancebo, G., Gayete, S., Corcoy, M. \& SoléSedeño, J.M. (2019) Role and impact of multimodal prehabilitation for gynecologic oncology patients in an Enhanced Recovery After Surgery (ERAS) program. Int. J. Gynecol. Cancer, 29, 1235-1243.

Morishita, S., Wakasugi, T., Tanaka, T., Harada, T., Kaida, K., Ikegame, K., Ogawa, H. \& Domen, K. (2018) Changes in Borg scale for resistance training and test of exercise tolerance in patients undergoing allogeneic hematopoietic stem cell transplantation. Support. Care Cancer, 26, 3217-3223.

Motoi, F. \& Unno, M. (2020) Adjuvant and neoadjuvant treatment for pancreatic adenocarcinoma. Jpn. J. Clin. Oncol., 50, 483-489.

Ngo-Huang, A., Parker, N.H., Wang, X., Petzel, M.Q.B., Fogelman, D., Schadler, K.L., Bruera, E., Fleming, J.B., Lee, J.E. \& Katz, M.H.G. (2017) Home-based exercise during preoperative therapy for pancreatic cancer. Langenbecks Arch. Surg., 402, 1175-1185.

Orr, J.L., Williamson, P., Anderson, W., Ross, R., McCafferty, S. \& Fettes, P. (2013) Cardiopulmonary exercise testing: arm crank vs cycle ergometry. Anaesthesia, 68, 497-501. 
Ouchi, Y., Rakugi, H., Arai, H., Akishita, M., Ito, H., Toba, K. \& Kai, I.; Joint Committee of Japan Gerontological Society (JGLS); Japan Geriatrics Society (JGS) on the definition and classification of the elderly (2017) Redefining the elderly as aged 75 years and older: proposal from the Joint Committee of Japan Gerontological Society and the Japan Geriatrics Society. Geriatr. Gerontol. Int., 17, 1045-1047.

Parker, N.H., Ngo-Huang, A., Lee, R.E., O’Connor, D.P., BasenEngquist, K.M., Petzel, M.Q.B., Wang, X., Xiao, L., Fogelman, D.R., Schadler, K.L., Simpson, R.J., Fleming, J.B., Lee, J.E., Varadhachary, G.R., Sahai, S.K., et al. (2019) Physical activity and exercise during preoperative pancreatic cancer treatment. Support. Care Cancer, 27, 2275-2284.

Patel, N., Powell, A.G., Wheat, J.R., Brown, C., Appadurai, I.R., Davies, R.G., Bailey, D.M. \& Lewis, W.G. (2019) Cardiopulmonary fitness predicts postoperative major morbidity after esophagectomy for patients with cancer. Physiol. Rep., 7, e14174.

Piraux, E., Caty, G. \& Reychler, G. (2018) Effects of preoperative combined aerobic and resistance exercise training in cancer patients undergoing tumour resection surgery: a systematic review of randomised trials. Surg. Oncol., 27, 584-594.

Quist, M., Sommer, M.S., Vibe-Petersen, J., Staerkind, M.B., Langer, S.W., Larsen, K.R., Trier, K., Christensen, M., Clementsen, P.F., Missel, M., Henriksen, C., Christensen, K.B., Lillelund, C., Langberg, H. \& Pedersen, J.H. (2018) Early initiated postoperative rehabilitation reduces fatigue in patients with operable lung cancer: a randomized trial. Lung Cancer, 126, 125-132.

Senda, J., Ito, K., Kotake, T., Kanamori, M., Kishimoto, H., Kadono, I., Nakagawa-Senda, H., Wakai, K., Katsuno, M., Nishida, Y., Ishiguro, N. \& Sobue, G. (2019) Cilostazol use is associated with FIM cognitive improvement during convalescent rehabilitation in patients with ischemic stroke: a retrospective study. Nagoya J. Med. Sci., 81, 359-373.

West, M.A., Loughney, L., Barben, C.P., Sripadam, R., Kemp, G.J., Grocott, M.P. \& Jack, S. (2014) The effects of neoadjuvant chemoradiotherapy on physical fitness and morbidity in rectal cancer surgery patients. Eur. J. Surg. Oncol., 40, 1421-1428.

Weisman, I.M., Marciniuk, D., Martinez, F.J., Sciurba, F., Sue, D., Myers, J. (2003). ATS/ACCP statement on cardiopulmonary exercise testing: II. indications for cardiopulmonary exercise testing. Am. J. Respir. Critical Care Med., 167, 211-277.

Wiskemann, J., Clauss, D., Tjaden, C., Hackert, T., Schneider, L., Ulrich, C.M. \& Steindorf, K. (2019) Progressive resistance training to impact physical fitness and body eeight in pancreatic cancer patients: a randomized controlled trial. Pancreas, 48, 257-266.

Yeo, T.P., Burrell, S.A., Sauter, P.K., Kennedy, E.P., Lavu, H., Leiby, B.E. \& Yeo, C.J. (2012) A progressive postresection walking program significantly improves fatigue and healthrelated quality of life in pancreas and periampullary cancer patients. J. Am. Coll. Surg., 214, 463-475; discussion 475-467. 